\title{
ASSESSMENT OF THE EFFECTIVENESS OF MEDICAL SIMULATORS IN THE PRACTICAL TRAINING OF MEDICAL STUDENTS: PRELIMINARY RESULTS IN MU-VARNA
}

\author{
Yanita Chernogorova, Deyan Grancharov, Zhivko Bliznakov \\ Simulation Center, Medical University of Varna
}

\begin{abstract}
INTRODUCTION: Nowadays, simulators have become part of most medical universities' educational strategy. In recent years, Medical University of Varna has been equipped with the most modern medical simulators, aiming to meet the practical training needs of all specialties taught at the university.

AIM: The aim of this study is to perform an initial assessment of the effectiveness in the use of simulators, as well as simulation-based training provided at the Medical University of Varna.

MATERIALS AND METHODS: We developed a set of criteria to evaluate the effectiveness of the simulation training including: simulators accessibility, complexity and safety, as well as training environment and trainers' preparedness. Based on these criteria, a questionnaire was developed and a survey conducted to study the students' opinion on the training quality with two medical simulators: dental and anesthesiology.

RESULTS AND CONCLUSION: Two groups of medical students - 73 students in dental medicine and 186 students in anesthesiology and intensive care, were enrolled in the study. The results showed a strong relationship between the students' specialty and simulation training in all evaluation criteria except one. The results revealed that medical simulators play an essential role in the practical training of medical students, and may substantially improve their future medical performance. Medical University of Varna effectively integrates simulation medicine into its educational program.
\end{abstract}

Keywords: medical simulators, practical training, simulation-based education, assessment of effectiveness

Address for correspondence:

Yanita Chernogorova

Medical University of Varna

55 Marin Drinov St

9002 Varna

e-mail: y.chernogorova@mu-varna.bg

Received: July 14, 2019

Accepted: September 8, 2019 


\section{INTRODUCTION}

The production of simulation equipment has been developing rapidly over the last two decades. Medical training simulators occupy a significant share in this sector. Nowadays, simulators have become part of most medical universities' educational strategies. In recent years, Medical University of Varna (http://www.mu-varna.bg) has been equipped with the most modern medical simulators, aiming to meet the practical training needs of all specialties taught at the university. According to Gaba (1), those working on the development and use of simulation in healthcare largely share a common vision for a future revolution in healthcare organizations, with simulation as a key enabling technique. As an educational strategy, simulation-based training provides an opportunity for effective learning and development of professional experience. Thus, to improve student education and ultimately improve patient safety, healthcare professionals use simulation in many forms, including simulated and virtual patients, static and interactive dummy simulators, training instructors, on-screen (computer) simulations, etc. (2). A major concern about simulation training is the lack of concrete evidence of its effectiveness in improving patient outcomes. Therefore, there is an urgent need to evaluate and quantify the benefits and effectiveness of simulation training in a systematic way (3).

We conducted a literature review on this topic, which included 42 articles published over the last 20 years and referenced by keywords as follows: simulators' effectiveness, medical simulators, education, universities, dental, anesthesia training simulators, etc. The search was carried out in referenced databases such as SCOPUS, Web of Science, PubMed, Library of Congress, LISTA (EBSCO), etc., as well as in the research organizations, annual universities journals, and websites in Bulgarian language. As a result of the literature review, four main approaches to simulation assessment have been differentiated: content analysis, comparative analysis, questionnaire survey, and evaluation framework.

Content analysis is a method used by several authors to evaluate the effectiveness of simulationbased training in medicine. In fact, this method is a literature analysis of publications, which evaluate the effectiveness of simulation-based training in comparison to other teaching or non-teaching methods (3-6).

Comparative analysis is a method for comparison of knowledge and skills between students who have undergone simulation training and those who attended only lectures is another method of analyzing the performance of simulators. For the purposes of the study presented by Knudson et. al., surgery trainees are randomly divided into two groups (7). One half go through a theoretical training course in a 5-part program. The other half are trained in the same program including the use of a simulator. The assessment of the knowledge of the trainees is based on a test (7-8).

Survey research is a widely used method of evaluating effectiveness - ranging from universityspecific research to large-scale studies conducted by international medical organizations. For instance, Agha et. al. (9) published the results of a study of satisfaction with simulation-based learning among $3^{\text {rd }}$ and $4^{\text {th }}$ year medical students. One of the strengths of the survey is the ability to conduct an online survey that covers a wider range of respondents (10).

For the purposes of analyzing the performance of simulators, the authors use different criteria. Some authors discuss the technical qualities of simulators in terms of reliability and validity. For example, computer simulations are complex and time-consuming, and it may be that a small number of simulation tests can be implemented in the time available for data collection (11). In 2015, Lioce et al., using the "design" criterion, take a similar approach. Simulation design promotes core processes and results that are consistent with program objectives (12).

\section{AIM}

The aim of this study is to perform an initial assessment of the effectiveness in the use of simulators, in a simulation-based training provided at the Medical University of Varna in the education of medical and dental medicine students.

\section{MATERIALS AND METHODS}

The evaluation framework applied in this study covers the following five criteria: simulator accessibility; complexity of simulator training features; work safety; training environment and trainers' pre- 
paredness (see Table 1). It aims to evaluate the effectiveness of simulation-based training organization as well as to determine the extent to which the related goals of the university's strategy are fulfilled.

Based on the above criteria, a questionnaire was developed and a survey was conducted to assess the students' opinion on the effectiveness of the simulators and simulation-based training. Two groups of students who had undergone simulation training were invited in the study - all of the 98 third-year students from the dental medicine (DM) program and all of the 400 fifth-year students from the medicine (M) program. Those groups were selected as simulation-based education is first introduced in the $3^{\text {rd }}$ year of dental medicine training and the availability of modern simulators for anesthesiology and intensive care training ensures good access to simulators to medical students in their $5^{\text {th }}$ year of education.

We performed descriptive statistical analysis with estimating percentages for qualitative vari-

Table 1. Evaluation framework

\begin{tabular}{|c|c|c|}
\hline $\begin{array}{l}\text { Evaluation } \\
\text { Criteria }\end{array}$ & Questions & University Objectives \\
\hline \multirow{3}{*}{ 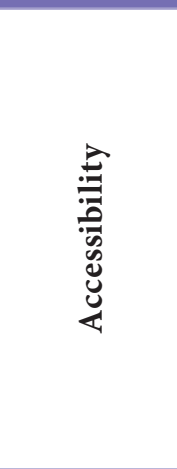 } & $\begin{array}{c}\text { During the simulation-based exercise, does each student have } \\
\text { the opportunity to work with a simulator? }\end{array}$ & $\begin{array}{l}\text { well organized practical training } \\
\text { with the simulators }\end{array}$ \\
\hline & $\begin{array}{l}\text { In your opinion, is there a need to provide additional simula- } \\
\text { tors at MU-Varna in order to increase the accessibility of stu- } \\
\text { dents to simulation training? }\end{array}$ & sufficient number of simulators \\
\hline & $\begin{array}{c}\text { Do you think that simulator-based exercises are sufficiently } \\
\text { integrated into the curriculum? }\end{array}$ & $\begin{array}{l}\text { increased availability of standard- } \\
\text { ized processes; enhancing expe- } \\
\text { rience; protecting real patients } \\
\text { from procedures performed by } \\
\text { inexperienced interns }\end{array}$ \\
\hline \multirow{2}{*}{ 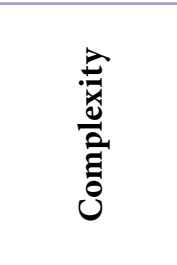 } & $\begin{array}{l}\text { Do the simulators used in your training recreate different } \\
\text { clinical conditions? }\end{array}$ & $\begin{array}{l}\text { possibility for realistic training in } \\
\text { a variety of case studies }\end{array}$ \\
\hline & $\begin{array}{l}\text { Does simulation-based training help you develop different } \\
\text { medical skills and competencies? }\end{array}$ & $\begin{array}{l}\text { good educational and material } \\
\text { facilities that enable students } \\
\text { to develop their knowledge and } \\
\text { skills }\end{array}$ \\
\hline \multirow{2}{*}{ 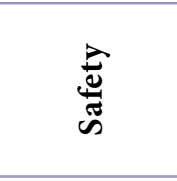 } & $\begin{array}{l}\text { Do the trainers at the simulators give you enough initial in- } \\
\text { structions before working with a new, unfamiliar simulator? }\end{array}$ & $\begin{array}{l}\text { ensuring safety working condi- } \\
\text { tions and training }\end{array}$ \\
\hline & $\begin{array}{c}\text { Do you have a trainer to monitor your work with the simula- } \\
\text { tors during the exercises? }\end{array}$ & $\begin{array}{l}\text { mastering the safety and techni- } \\
\text { cal expertise }\end{array}$ \\
\hline \multirow{2}{*}{ 此苞 } & $\begin{array}{c}\text { Do you think that the simulators used in your training could } \\
\text { be placed in a more realistic, i.e. close to clinical conditions, } \\
\text { environment? }\end{array}$ & mastering routine medical skills \\
\hline & $\begin{array}{l}\text { In your opinion, does building a specialized Simulation Cen- } \\
\text { ter (with halls with realistic clinical environment; control } \\
\text { rooms for simulator management; observation and discussion } \\
\text { halls) would increase the effectiveness of simulation training? }\end{array}$ & $\begin{array}{l}\text { quality education with innova- } \\
\text { tive tools }\end{array}$ \\
\hline \multirow{2}{*}{ 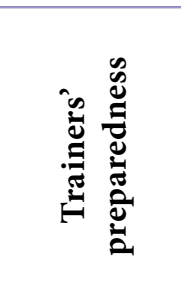 } & $\begin{array}{l}\text { Is the number of trainers enough to provide you with simula- } \\
\text { tion-based training? }\end{array}$ & $\begin{array}{l}\text { more efficient management of all } \\
\text { types of resources and reduced } \\
\text { training time }\end{array}$ \\
\hline & $\begin{array}{c}\text { Do you think that well-organized simulation training re- } \\
\text { quires a team of two trainers - a simulator maintenance / } \\
\text { training engineer and a medical practitioner to conduct the } \\
\text { exercise? }\end{array}$ & $\begin{array}{l}\text { utilizing the full capabilities of } \\
\text { the simulators - for example, stor- } \\
\text { ing and analyzing performance } \\
\text { data }\end{array}$ \\
\hline
\end{tabular}


ables. Association between the medical specialty and the simulation-based training evaluation criteria was tested with $\chi^{2}$ test. The level for statistical significance was set at $\alpha=0.05$. Analysis were performed with statistical package IBM SPSS version 19.

\section{RESULTS AND DISCUSSION}

A total of 259 students - 73 students in dental medicine and 186 medical students, responded to the invitation and were included in this study. They completed the questionnaire at the end of their practical exercises with simulators.

The analysis showed a significant association between the studied specialty (M or DM) and all simulation training evaluation criteria, except for Trainers' Preparedness.

With respect to the first criterion Accessibility, 48 units of DSE Expert simulators are provided to $3^{\text {rd }}$-year dental medicine students for their practical training. For $5^{\text {th }}$-year medical students, the University equipped practical exercises with two different simulators - iSTAN and APOLLO adult patient simulator, each with its own advantages. Students (M and DM) spent 2 working hours with simulators per week. The adequate provision is the cause for the very high proportion of students from both specialties to report that they have access to a simulator during their practical exercises $-92 \%$ for medical and $85 \%$ for dental medicine students $\left(\chi^{2}=2.012, \mathrm{p}=0.156\right)$ (Fig. 1). Despite the higher number of simulators in DM education, a smaller percentage of DM students declare an opportunity to practice on a simulator during their exercises. The comments given by the dental medicine students at the end of the questionnaires explain this contradiction. Students mention a limited number of provided materials: forceps, sector rings, borers, matrices, wedges, gloves, etc., which results in slower execution of the exercises. As a result, some DM students are not able to complete their exercises on the phantom heads in the time available. The higher percentage of medical students reporting good accessibility to simulators is due to the fact that: (a) medical students' groups are twice as small as those of DM students, (b) teams of two or three medical students work together with a simulator, (c) simulators for medical students do not need additional supplies, and different patient conditions are easily simulated.
Despite the above results for wide access to simulators of medical students, $65 \%$ of them recommend additional simulators to be provided, against $37 \%$ of DM students $(\mathrm{p}<0.05)$.

The answer on the third aspect of the criteria Accessibility indicates that simulators are better integrated in the medical students' curriculum and their education in the discipline anesthesiology and intensive care with greater number of exercises than those provided to dental medicine students. Almost half of the medical students (42\%) think that simulator-based exercises are well integrated into their education as compared with less than one-fourth (24\%) from DM $(\mathrm{p}<0.05)$. Students' opinion regarding the Accessibility criterion is shown on Fig. 1.

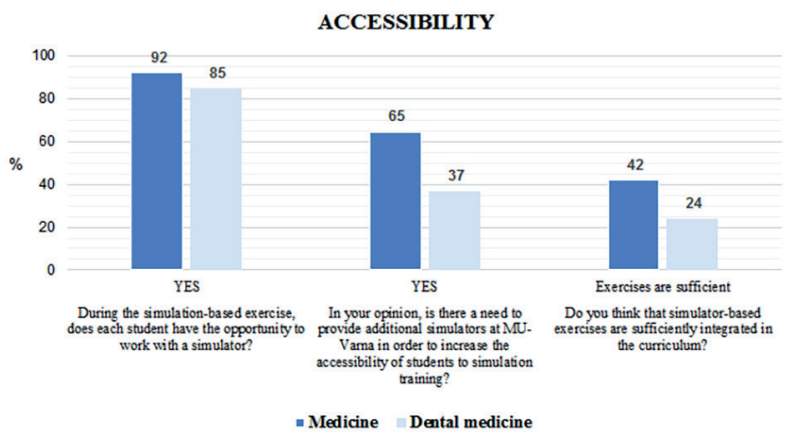

Fig. 1. Students' opinion regarding the Accessibility criterion

Regarding the next criterion of the simulator training features - Complexity, a lot has been achieved at the Medical University of Varna in the recent years. Sophisticated, complex simulators with comprehensive technical features are provided and used by medical students. Both iSTAN and APOLLO simulators are equipped with additional applications supporting different clinical cases, scenarios, and conditions. The DSE Expert simulators provided for dental medicine students are freely combinable with jaw simulators, face masks, and face bows. The available up-to-date simulation technique for both specialties has a potential for constant upgrade characterizing it as highly complex. All this is supported by the positive answers of both specialties to the question: "Do the simulators used in your training recreate different clinical conditions?" - 96\% for medical and $75 \%$ for DM students. 
Almost $100 \%$ of the respondents appreciate the various skills and competencies developed with the simulation training (Fig. 2). Such a result suggested that simulation-based training boosts a university's objective to provide good educational and material facilities that enable students to advance their knowledge and skills.

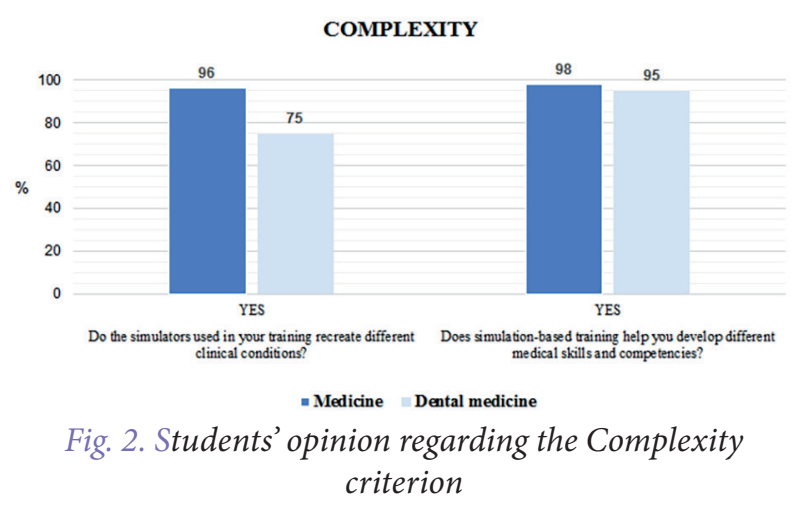

Work safety should be a leading characteristic and factor in any university and healthcare activity and involves the protection of students, all employees, and visitors of the institution. Safety effectiveness assessment should never be compromised, and the criterion underlies the university's quality management policy. The Safety component of the simulation training effectiveness was evaluated with two questions. The results are very much self-explanatory (Fig. 3).

Initial instructions regarding work safety are provided according to almost all students, both medical (88\%) and dental medicine (92\%). The presence of an instructor during the simulation training is required and provided according to $97 \%$ of medical students as compared with $90 \%$ of dental medicine

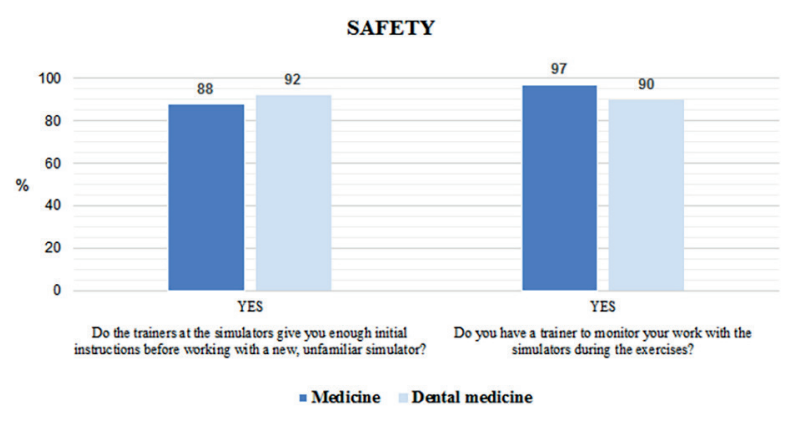

Fig. 3. Students' opinion regarding the Safety criterion students $(\mathrm{p}<0.05)$. As mentioned above, medical students practice by working in a team, which allows the trainers to monitor, control and ensure safety during their work throughout the exercise. In comparison, dental medicine students work individually, and trainers monitor their safety while working from aside and guide them if/when needed.

The fourth evaluation criterion, Training Environment, is also an important aspect in the ensuring of simulation training effectiveness. It is considered especially valuable in the present study in the context of a forthcoming planned construction of a dedicated simulation center at the Medical University of Varna.

The lack of realism experience (physical resemblance and functional task alignment) of the respondents is a barrier for linking the importance of fidelity of the training simulation environment with a quality learning experience.

Although a quarter of the medical (25\%) and one-third (34\%) of the dental medicine students find it difficult to assess the environment, many respondents believe that the environment and, respectively, the quality of simulation training can be improved by building a specialized simulation center $(60 \%$ for medical and 47\% for DM students) (Fig. 4).

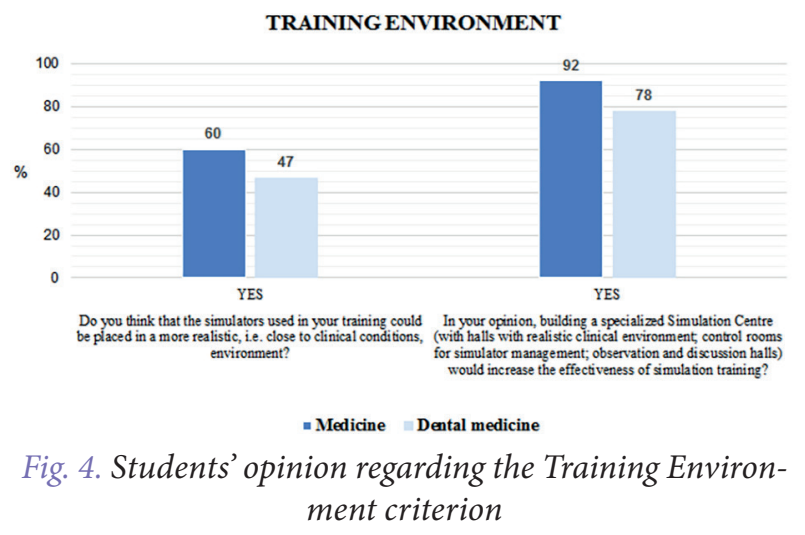

More than three quarters (78\%) of the DM students and $92 \%$ of the medical students believe that well-known environment reduces stress and eases adaptation to the clinical setting, thus increasing concentration on patient care $(\mathrm{p}<0.05)$. The most recently established university simulation training sector is the one for dental medicine students. Extreme- 
ly well-designed learning environment for these students as well as state-of-the-art dental simulation full treatment workstation have provided the defined differences in the response rate given by both group of students.

Environmental assessment questions are a good basis for further analysis and comparison of opinions taken before and after the actual building of the simulation center.

The last criterion Trainers' Preparedness to work as instructors concerns the required qualification of instructors and the quality of education, respectively. It is the only criterion that showed no significant association with a student's specialty. The tests have revealed adequate preparedness of the involved academic staff according to students' opinion from both specialties ( $\mathrm{p}=0.099)$ (Fig. 5). Students agree that better training results will be achieved under the guidance of a team of trainers with medical and technical expertise $(\mathrm{p}=0.754)$.

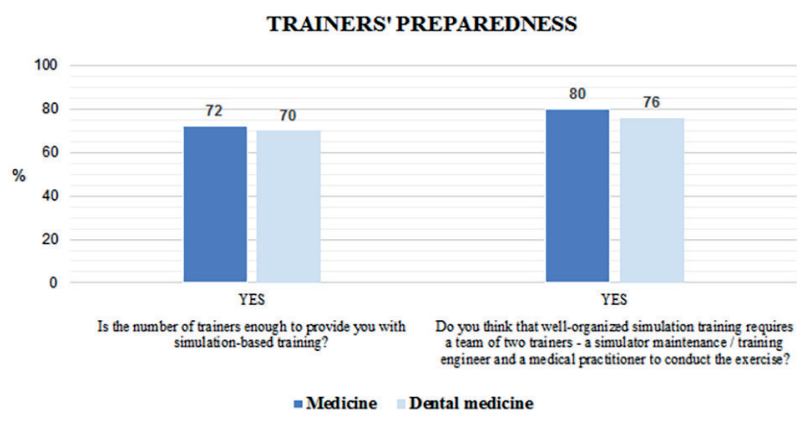

Fig. 5. Students' opinion regarding the Trainers' Preparedness criterion

\section{CONCLUSION}

This paper presents an evaluation framework using five criteria for the effectiveness of the simulation-based training delivered at the Medical University of Varna, Bulgaria. The criteria in this framework are subject to change with each successive evaluation according to the objectives, which measure the effectiveness.

In general, expressed as a percentage, the results of the analysis show that all set up by the Medical University of Varna goals linked to simulationbased training and its organization have been met effectively. The only unsatisfactory results concern the volume of practical training in the curriculum. In this regard, the current project of Medical University of Varna related to developing a dedicated Simulation Center is considered developed on time and would improve effectiveness in terms of: (a) accessibility by better organization and exercise management, (b) complexity by providing a video recording of the exercises for analysis and discussion, (c) more realistic training environment, (d) advanced skills and experience of the trainers.

On the other hand, the SPSS analysis determined half of the examined variables as associated with the student specialty, which must be taken into account in the subsequent effectiveness evaluation framework development.

The future work includes: (a) actions to explore the managerial experience of other simulation centers in order to improve the organization of practical training, (b) selection of different evaluation criteria according to the specificity of the specialty, (c) a comparative analysis of students' opinions taken before and after the construction of the Simulation Center at the Medical University of Varna.

\section{REFERENCES}

1. Gaba DM. The future vision of simulation in health care. Qual Saf Health Care. 2004; 13 Suppl 1: I2I10. doi: 10.1136/qhc.13.suppl_1.i2.

2. Aggarwal R, Mytton OT, Derbrew M, Hananel D, Heydenburg M, Issenberg B, et al. Training and simulation for patient safety. Qual Saf Health Care. 2010; 19 Suppl 2: i34-43. doi: 10.1136/ qshc.2009.038562.

3. So HY, Chen PP, Wong GK, Chan TT. Simulation in medical education. J R Coll Physicians Edinb. 2019; 49(1):52-7. doi: 10.4997/JRCPE.2019.112.

4. Beal MD, Kinnear J, Anderson CR, Martin TD, Wamboldt R, Hooper L. The effectiveness of medical simulation in teaching medical students critical care medicine: A systematic review and meta-analysis. Simul Healthc. 2017; 12(2):104-16. doi: 10.1097/ SIH.0000000000000189.

5. Kim J, Park JH, Shin S. Effectiveness of simulationbased nursing education depending on fidelity: a meta-analysis. BMC Med Educ. 2016; 16:152. doi: 10.1186/s12909-016-0672-7. 
6. Alanazi A, Nicholson N, Thomas S. The use of simulation training to improve knowledge, skills, and confidence among healthcare students: A systematic review. Internet J Allied Health Sci Pract. 2017; 15(3).

7. Knudson M, Khaw L, Bullard M, Dicker R, Cohen $\mathrm{M}$, Staudenmayer K, et al. Trauma training in simulation: Translating skills from SIM time to real time. Journal Trauma. 2008; 64(2):255-63; discussion 263. doi: 10.1097/TA.0b013e31816275b0.

8. Ismail $M$, Jaafar M, Harunarashid $H$ (2011). The effectiveness of simulation based medical education in teaching concepts of major incident response. Procedia Soc Behav Sci. 2011; 18: 372-8. doi: 10.1016/j.sbspro.2011.05.053.

9. Agha S, Alhamrani AY, Khan MA. Satisfaction of medical students with simulation based learning. Saudi Med J. 2015; 36(6):731-6. doi: 10.15537/ smj.2015.6.11501.
10. Qayumi, K, Pachev G, Zheng B, Ziv A, Koval V, Badiei S, et al. Status of simulation in health care education: an international survey. Adv Med Educ Pract. 2014; 5:457-67. doi: 10.2147/AMEP.S65451. e.

11. Bewley WL, O’Neil HF. Evaluation of medical simulations. Mil Med. 2013; 178(10 Suppl): 64-75. doi: 10.7205/MILMED-D-13-00255.

12. Lioce L, Meakim CH, Fey MK, Chmil JV, Mariani B, Alinier G (2015). Standards of best practice: Simulation Standard IX: Simulation design. Clin Simul Nurs. 2015; 11(6): 309-15. doi:10.1016/j. ecns.2015.03.005. 